\title{
Maxillomandibular Advancement in Obstructive Sleep Apnea Syndrome Patients: a Restrospective Study on the Sagittal Cephalometric Variables
}

\author{
Paolo Ronchi $^{1}$, Valentina Cinquini ${ }^{2}$, Alessandro Ambrosoli ${ }^{2}$, Alberto Caprioglio ${ }^{2}$ \\ ${ }^{1}$ Maxillofacial Surgery Unit, Sant'Anna Hospital Como, Italy. \\ ${ }^{2}$ Department of Orthodontics, School of Dentistry, University of Insubria, Varese, Italy.
}

\author{
Corresponding Author: \\ Valentina Cinquini \\ Via Buia 34, 55100 Lucca \\ Italy \\ Phone: (0039) 3498486159 \\ Fax: (0039) 0583496325 \\ E-mail: valentinacinquini@yahoo.it
}

\begin{abstract}
Objectives: The present retrospective study analyzes sagittal cephalometric changes in patients affected by obstructive sleep apnea syndrome submitted to maxillomandubular advancement.

Material and Methods: 15 adult sleep apnea syndrome (OSAS) patients diagnosed by polysomnography (PSG) and treated with maxillomandubular advancement (MMA) were included in this study. Pre- (T1) and postsurgical (T2) PSG studies assessing the apnea/hypopnea index (AHI) and the lowest oxygen saturation (LSAT) level were compared. Lateral cephalometric radiographs at T1 and T2 measuring sagittal cephalometric variables (SNA, SNB, and ANB) were analyzed, as were the amount of maxillary and mandibular advancement (Co-A and Co-Pog), the distance from the mandibular plane to the most anterior point of the hyoid bone (Mp-H), and the posterior airway space (PAS).

Results: Postoperatively, the overall mean AHI dropped from $58.7 \pm 16$ to $8.1 \pm 7.8$ events per hour $(\mathrm{P}<0.001)$. The mean preoperative LSAT increased from $71 \%$ preoperatively to $90 \%$ after surgery $(\mathrm{P}<0.001)$. All the patients in our study were successfully treated (AHI $<20$ or reduced by $50 \%$ ). Cephalometric analysis performed after surgery showed a statistically significant correlation between the mean SNA variation and the decrease in the AHI $(\mathrm{P}=0.01)$. The overall mean SNA increase was $6^{\circ}$.

Conclusions: Our findings suggest that the improvement observed in the respiratory symptoms, namely the apnea/hypopnea episodes, is correlated with the SNA increase after surgery. This finding may help maxillofacial surgeons to establish selective criteria for the surgical approach to sleep apnea syndrome patients.
\end{abstract}

Keywords: sleep apnea syndromes; orthognathic surgery; mandibular advancement; cephalometry.

Accepted for publication: 29 June 2013

To cite this article:

Ronchi P, Cinquini V, Ambrosoli A, Caprioglio A. Maxillomandibular Advancement in Obstructive Sleep Apnea Syndrome Patients: a Restrospective Study on the Sagittal Cephalometric Variables.

URL: http://www.ejomr.org/JOMR/archives/2013/2/e5/v4n2e5ht.pdf

doi: $10.5037 /$ jomr.2013.4205 


\section{INTRODUCTION}

Obstructive sleep apnea syndrome (OSAS), which is caused by a complete or partial obstruction of the upper airway producing apnea or hypopnea, is a sleep disorder characterized by repetitive cessation of breathing occurring during sleep [1]. According to the American Academy of Sleep Medicine, a diagnosis of OSAS can be made in the presence of five or more episodes of apnea/hypopnea per hour of sleep, accompanied by clinical symptoms (such as daytime sleepiness, mood disorder, insomnia, hypertension), or at least 15 events per hour without additional symptoms. OSAS is defined as mild when characterized by 5 - 15 events per hour, moderate in the presence of up to 30 events per hour, and severe when these number more than 30 [2].

The pathogenesis of OSAS is multifactorial, however two main categories are described in the literature that, in some cases, can occur in combination. The first, and more common, form is due to obstruction of the respiratory lumen, for example at the level of the retropalatal and retroglossal spaces, involving the soft palate and the base of the tongue [3]. This obstruction, which can be partial or total, is linked to tissue factors such as tonsillar hypertrophy, but also to obesity, which can determine fatty infiltration of the pharyngeal wall $[\underline{4}, \underline{5}]$. The second, less frequent form is central OSAS, which is due to dysfunction of the cerebral mechanisms that control the pharyngeal muscles that keep the airways open during sleep. In this case, suppression of nerve impulses results in a narrower airspace that is more prone to collapsing on inspiration during sleep [6]. Certain skeletal abnormalities, such as reduced sagittal linear dimensions of the cranial base, of the maxilla, and also of the bony naso-oropharynx, can also predispose to OSAS. Retrognathia of both the maxilla and the mandible and increased lower face height frequently show a strong relationship with OSAS [7]. In addition, in OSAS subjects the hyoid bone is located more inferiorly, between the fourth and the sixth cervical vertebra, and the intermaxillary space length (the distance between the posterior pharyngeal wall and the tip of the lower incisor) is reduced. These alterations decrease the tongue space, causing it to lie in a lower and a more posterior position, where it causes partial or total obstruction of the pharyngeal lumen during sleep []]. Due to repeated apnea/hypopnea episodes, OSAS patients have disturbed and less restorative sleep, and thus present several characteristic symptoms, such as daytime sleepiness associated with a higher risk of motor vehicle accidents, morning headache, mood disorder, depression and lack of libido $[9,10]$. They also have an increased incidence of medical comorbidities (e.g. hypertension, stroke, death) [11].

In the initial therapeutic approach, OSAS patients are encouraged to make lifestyle changes, for instance, to lose weight (in the case of obese patients), but also to stop using alcohol or other agents that can facilitate collapse of the upper airway. However, the main therapeutic options also include continuous positive airway pressure (C-PAP) therapy, oral appliances and surgical procedures [12]. C-PAP therapy is based on the maintenance of constant air pressure, preventing the collapse of the upper airway during sleep, and it is recommended for subjects with an upper airway obstruction. It is currently the gold standard noninvasive treatment for OSAS, but it is not indicated in patients with nasal obstruction or claustrophobia $[13,14]$. The CPAP machine is quite voluminous and it must be used every night; this treatment has a high therapeutic efficacy but it is poorly tolerated and refused by $50 \%$ of patients [13]. Other therapeutic strategies are the use of oral mandibular repositioning appliances, usually better tolerated by patients, but successful only in the treatment of mild-to-moderate cases of sleep apnea. These appliances cover the upper and lower teeth and hold the mandible in an advanced position, thus widening the upper airway [14].

Surgical therapy includes a variety of upper airway reconstructive or skeletal procedures. Surgical modifications of the soft tissue of the upper airway e.g. uvulopalatopharyngoplasty (UPPP), partial midline glossectomy and radiofrequency volumetric tissue reduction - were, in the past, commonly used to increase the posterior airway space in severe OSAS [15]. Orthognathic surgical procedures, on the other hand, consist of: anterior inferior mandibular sagittal osteotomy (genioglossal advancement), which, together with hyoid suspension, constitutes phase I surgery, genioplasty, and maxillomandibular advancement osteotomies [15]. Maxillomandibular advancement (MMA) is used for OSAS patients with dentofacial deformities requiring orthognathic surgery and/or for those with extremely severe obstructive disease, in whom all applicable conservative therapies have failed or proved intolerable [16]. MMA is the most effective surgical therapy for OSAS $[13,17]$. It consists of Le Fort I osteotomy of the maxilla and a bilateral sagittal split osteotomy of the mandible producing simultaneous advancement of both the maxilla and the mandible, and of the soft tissue overlying these structures. This procedure, by modifying the pharyngeal structures and the tongue space, increases the dimension of the upper airway and thus reduces the risk of pharyngeal collapse during negative pressure inspiration $[18,19]$. This method is sometimes associated with anticlockwise rotation of the occlusal plane that advances the soft 
palate [20]. Recently $\mathrm{Li}$ [21] reported a success rate of $89 \%$, and Prinsell [22], too, demonstrated that MMA is a highly effective treatment with a success rate of between $86.5 \%$ and $86.6 \%$. For this reason it can be considered the surgical treatment of choice that is able, especially when performed in young patients, to significantly improve the quality of life of individuals with OSAS. This study set out to evaluate the effects of MMA on OSAS patients treated with orthognathic surgery; specifically, its aim was to establish which cephalometric variables can influence changes in respiratory symptoms.

\section{MATERIAL AND METHODS}

This retrospective study analyzed 15 patients (11 males and 4 females) from an initial pool of 27 patients (Table 1), who had clinical and polysomnographic evidence of moderate (1 subject) or severe (14 subjects) OSAS and were submitted to orthognathic surgery as detailed in Table 2. The mean age of the 15 patients who underwent MMA was $42.3 \pm 9.5$ years (range from 26.3 to 62.5 years). On the basis of ANB, nine patients were deemed to have presurgical skeletal Class II malocclusion (ANB $>4^{\circ}$ ), five patients Class I malocclusion ( $\mathrm{ANB}=2^{\circ} \pm 2^{\circ}$ ), and only one patient Class III $\left(\mathrm{ANB}<0^{\circ}\right)$ malocclusion. All the patients had already undergone other non-invasive treatments that had been unsuccessful (oral appliances) or had been rejected in the long term (C-PAP). All were medically stable enough to undergo orthognathic surgery. All the subjects included in this study were adults referred from the Department of Maxillofacial Surgery of the Sant'Anna Hospital in Como, Italy. Each patient was evaluated with nocturnal polysomnoraphy (PSG) and lateral cephalometric radiographs preoperatively (T1) and after the surgery (T2). All underwent orthodontic treatment in parallel with surgery. The variables taken into account were: age, gender, apnea/hypopnea index (AHI), lowest oxygen saturation (LSAT) level, and cephalometric data.

\section{Polysomnography}

PSG was performed at the Sleep Center of the San Raffaele Hospital in Milan and at the Department of Sleep Medicine of the Felice Villa Hospital in Mariano Comense (Co) using a SomnoCheck
Effort polygraph (Weinmann, Hamburg, Germany). The following variables were measured for each patient: AHI, as measure of therapeutic efficacy, and LSAT. These variables were used to determine the presence and severity of OSAS before surgery and to establish (on the basis of changes in the PSG variables after surgery) the clinical effectiveness of the therapy.

\section{Cephalometric analysis}

Pre- and postoperative lateral cephalometric radiographs for each patient were taken with the teeth in occlusion and following a standardized procedure. The cephalometric examination was carried out with a standardization of the magnification factor, and each cephalogram was double hand-traced by two different investigators who were unaware of the clinical results. The landmarks used in this study are shown in Figure 1.

Table 1. Selection and exclusion criteria used to recruit OSAS patients

\begin{tabular}{c|c}
\hline Sample selection & No. of OSAS patients \\
\hline Patient sample & 27 \\
1. Incomplete records & 8 \\
2. Poor film quality $\quad 3$ \\
\hline Secondary exclusion criteria \\
3. Use of concomitant C-PAP \\
\hline Final sample
\end{tabular}

$\mathrm{C}-\mathrm{PAP}=$ continuous positive airway pressure therapy.

Table 2. Pre- and postoperative polysomnographic recordings

\begin{tabular}{c|c|c|c|c|c}
\hline \multirow{2}{*}{$\begin{array}{c}\text { Patient } \\
\text { No. }\end{array}$} & \multirow{2}{*}{ Sex } & \multicolumn{2}{|c|}{ AHI } & \multicolumn{2}{c}{ LSAT } \\
\cline { 3 - 6 } & & Preoperative & Postoperative & Preoperative & Postoperative \\
\hline $\mathbf{1}$ & $\mathrm{M}$ & 31 & 3 & $87 \%$ & $93 \%$ \\
\hline $\mathbf{2}$ & $\mathrm{M}$ & 44 & 7 & $79 \%$ & $90 \%$ \\
\hline $\mathbf{3}$ & $\mathrm{M}$ & 57 & 11 & $62 \%$ & $82 \%$ \\
\hline $\mathbf{4}$ & $\mathrm{M}$ & 69 & 4 & $83 \%$ & $92 \%$ \\
\hline $\mathbf{5}$ & $\mathrm{M}$ & 70 & 5 & $76 \%$ & $88 \%$ \\
\hline $\mathbf{6}$ & $\mathrm{F}$ & 79 & 30 & $62 \%$ & $88 \%$ \\
\hline $\mathbf{7}$ & $\mathrm{F}$ & 62 & 4 & $66 \%$ & $73 \%$ \\
\hline $\mathbf{8}$ & $\mathrm{M}$ & 25 & 3 & $80 \%$ & $89 \%$ \\
\hline $\mathbf{9}$ & $\mathrm{F}$ & 73 & 4 & $84 \%$ & $84 \%$ \\
\hline $\mathbf{1 0}$ & $\mathrm{M}$ & 60 & 4 & $78 \%$ & $85 \%$ \\
\hline $\mathbf{1 1}$ & $\mathrm{M}$ & 51 & 5 & $69 \%$ & $91 \%$ \\
\hline $\mathbf{1 2}$ & $\mathrm{M}$ & 70 & 3 & $56 \%$ & $92 \%$ \\
\hline $\mathbf{1 3}$ & $\mathrm{M}$ & 71 & 22 & $62 \%$ & $77 \%$ \\
\hline $\mathbf{1 4}$ & $\mathrm{F}$ & 48 & 8 & $85 \%$ & $86 \%$ \\
\hline $\mathbf{1 5}$ & $\mathrm{M}$ & 70 & 8 & $79 \%$ & $88 \%$ \\
\hline Mean & - & 58.7 & 8.1 & $71 \%$ & $90 \%$ \\
\hline & & & & & \\
\hline
\end{tabular}

$\mathrm{AHI}=$ Apnea/hypopnea index $; \mathrm{LSAT}=$ lowest oxygen saturation; $\mathrm{M}=$ male $; \mathrm{F}=$ female 


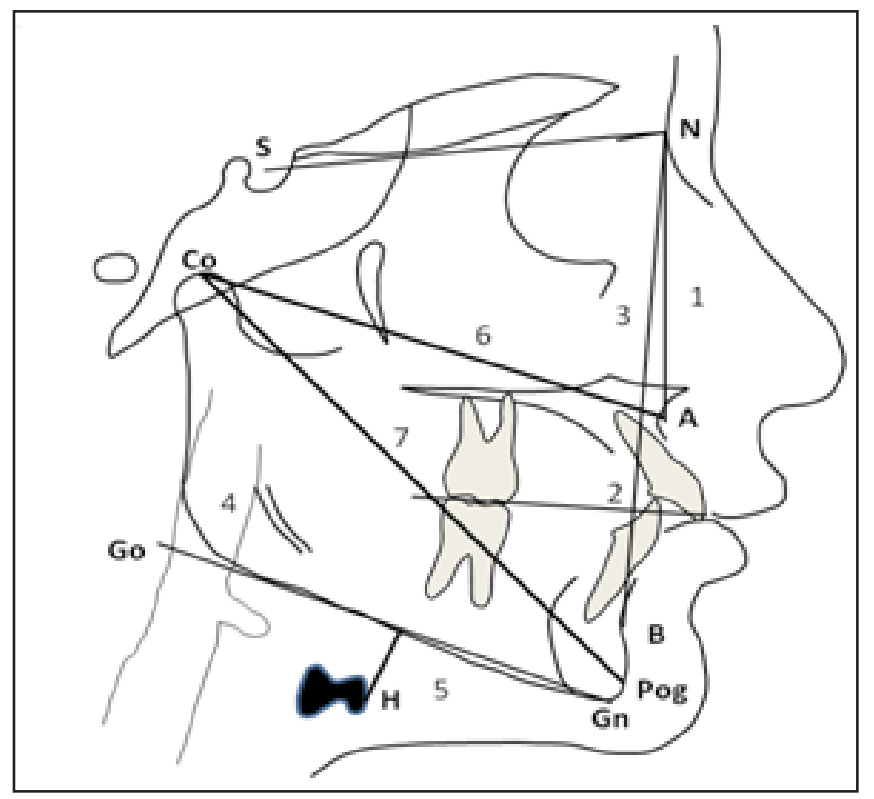

Figure 1. Cephalometric variables measured:

$1=$ SNA (angle between sella, nasion and subspinale point A); $2=$ SNB (angle between sella, nasion and supramentale point $\mathrm{B}$ ); $3=$ ANB (angle between the maxilla and the mandible);

$4=$ PAS (the narrowest distance between the base of the tongue and the posterior pharyngeal wall);

$5=\mathrm{MP}-\mathrm{H}$ (distance from the mandibular plane to the most anterior point of the hyoid bone);

$6=\mathrm{Co}-\mathrm{A}$ (amount of the maxillary advancement);

$7=$ Co-Pog (amount of mandibular advancement).

The following linear and angular variables were analyzed: SNA (angle between the sella, nasion and subspinale point A), SNB (angle between the sella, nasion and supramentale point $\mathrm{B}$ ), ANB (angle between the maxilla and the mandible), PAS (the narrowest distance between the base of the tongue and the posterior pharyngeal wall - a measurement used to detect pharyngeal obstruction), MP-H (distance from the mandibular plane to the most anterior point of the hyoid bone), Co-A (the amount of maxillary advancement) and Co-Pog (the amount of mandibular advancement).

\section{Surgical procedure}

The surgical procedure consisted of Le Fort I advancement and bilateral mandibular sagittal split osteotomies (Figure 2, Figure 3A, B). Rigid fixations were used in all patients to hold the bones in their new position: microplates at the maxilla and miniplates with monocortical screws at the mandible (Synthes CMF, Missisauga, Ontario, Canada). No patient underwent maxillomandibular fixation, but all underwent advancement genioplasty according to Prinsell [23] The postsurgical assessment was performed within one year of surgery. It consisted of a clinical followup, a radiological evaluation with orthopantomography and lateral cephalometric radiographs, and a PSG

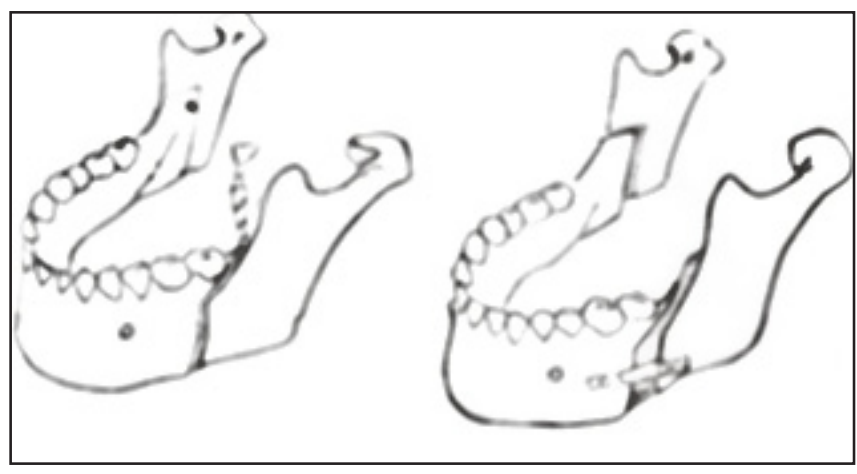

Figure 2. Mandibular advancement.

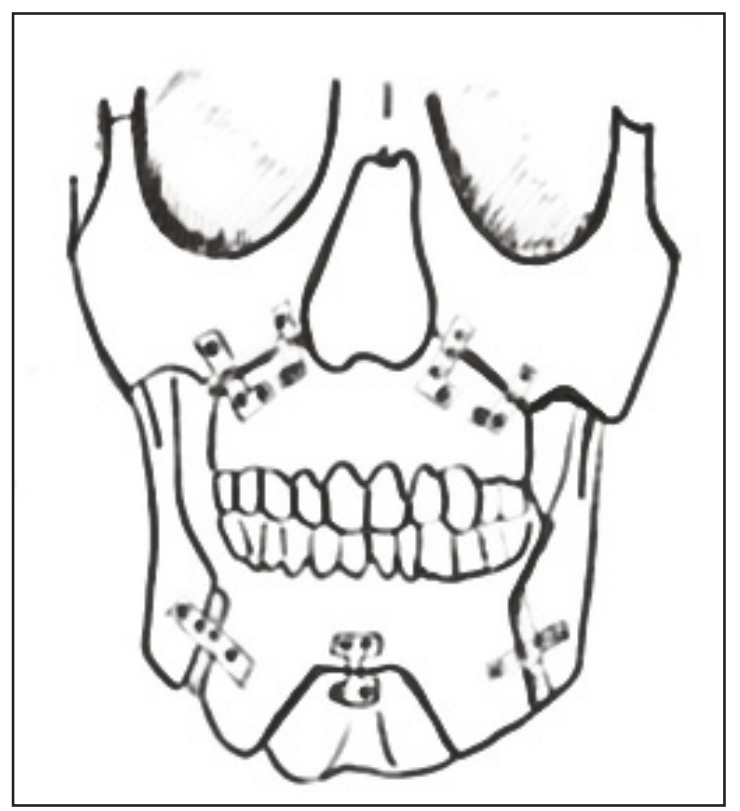

Figure 3A. Bimaxillary advancement (frontal view).

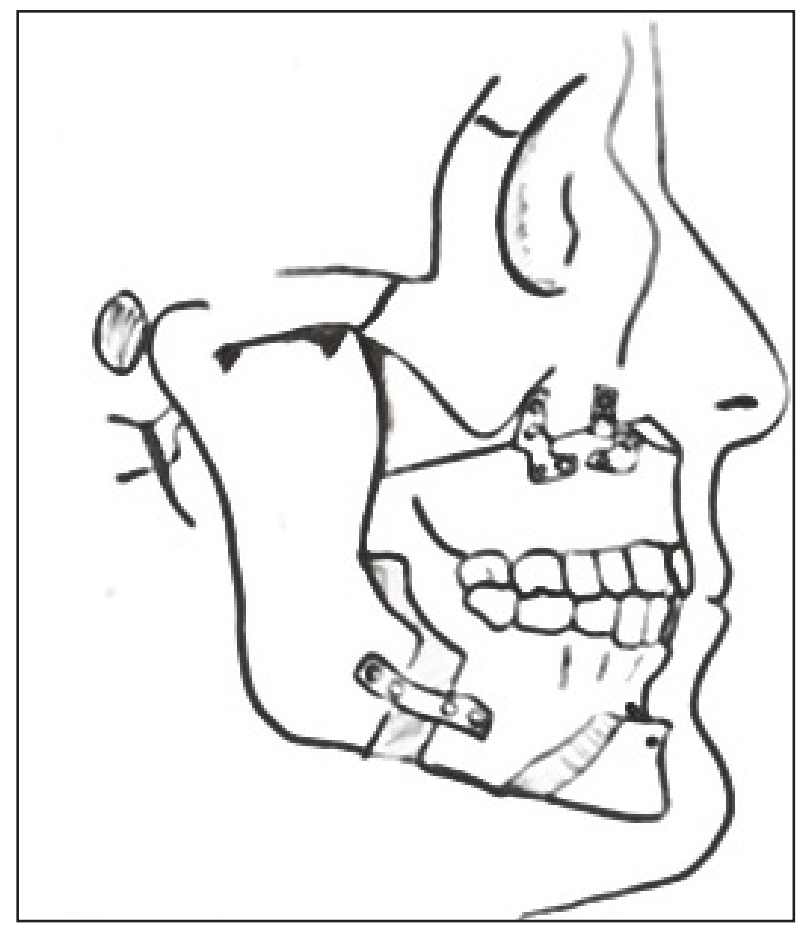

Figure 3B. Bimaxillary advancement (profile view). 
assessment. MMA, whose amount depended on the initial craniofacial characteristics, was evaluated in each patient.

\section{Statistical analysis}

Descriptive statistical analysis was performed for all demographic variables (age and gender) and outcome variables at $\mathrm{T} 1$ and $\mathrm{T} 2$. The Wilcoxon signed rank test was used to determine the correlation between the PSG variables and the cephalometric variables for each outcome measure, and $\mathrm{P}<0.05$ was considered statistically significant for all analyses. In addition, pre- versus postoperative reduction in the AHI was calculated to establish the treatment effectiveness.

\section{Method error}

Each radiograph was traced by two different operators at different times. Application of the paired t-test revealed no significant mean differences between the two series of records. Dalhberg's formula was used to assess the method error [24]. Errors were normally less than one unit, ranging from 0.2 to $0.8 \mathrm{~mm}$ for linear measurements and from $0.4^{\circ}$ to $1^{\circ}$ for angular measurements, corresponding of a coefficient of reliability of $96 \%$ [25].

\section{RESULTS}

\section{Effect of MMA on OSAS}

Table 2 shows preoperative and postoperative AHI and LSAT values with corresponding percentage changes. Postoperatively, the overall mean AHI dropped from $58.7 \pm 16$ to $8.1 \pm 7.8$ events per hour $(\mathrm{P}<0.001)$. The mean preoperative LSAT increased from $71 \%$ preoperatively to $90 \%$ after surgery $(\mathrm{P}<0.001)$.

\section{Cephalometric analysis}

Lateral cephalometric radiographic evaluation (Table 3) showed mean preoperative SNA and SNB values of $79.9^{\circ} \pm 5.8^{\circ}$ and $74.3^{\circ} \pm 4.9^{\circ}$ respectively; the mean postoperative values were $85.9^{\circ} \pm 5.8^{\circ}$ and $78.5^{\circ}$ $\pm 5.0^{\circ}$, respectively. The mean overall amount of maxillary advancement measured on X-ray was $5.2 \mathrm{~mm}$ $( \pm 4.5 \mathrm{~mm}$ ), ranging from $0 \mathrm{~mm}$ to $14 \mathrm{~mm}$. The mean amount of mandibular advancement measured on X-ray was $9.5 \mathrm{~mm}( \pm 8.7 \mathrm{~mm})$, ranging from - 2 to $29 \mathrm{~mm}$. Postoperative cephalometric analysis (Table 4) showed a statistically significant average variation $(\mathrm{P}=0.01)$ of the SNA which correlated with the decrease in the AHI. The mean SNA variation was $6^{\circ}$ (falling from $79.9^{\circ} \pm 5.8^{\circ}$ to $85.9^{\circ} \pm 5.8^{\circ}$ ). In addition, the increase in LSAT was found to show a statistically significant correlation both with the amount of maxillary advancement $(\mathrm{P}=0.03)$ and with the amount of mandibular advancement $(\mathrm{P}=$ 0.029). In particular, the results show that for each $\mathrm{mm}$ of Co-A and Co-Pog increase there was a $1 \%$ increase in LSAT. No statistically significant correlations were found between the PSG parameter AHI and the SNB $(\mathrm{P}=0.07)$, ANB $(\mathrm{P}=0.33)$, PAS $(\mathrm{P}=0.74)$ and $\mathrm{MP}-\mathrm{H}$ $(\mathrm{P}=0.16)$. The position of the hyoid was recorded in relation to the mandible, and the mean distance from the hyoid to the mandible plane was increased by 1.3 $\mathrm{mm}$ (from $28.2 \mathrm{~mm}$ to $29.5 \mathrm{~mm}$ ) on the post-treatment $\mathrm{X}$-ray. This change was not statistically significant. The PAS increased from $5 \pm 2.2 \mathrm{~mm}$ to $9.5 \pm 3.3 \mathrm{~mm}$.

\section{DISCUSSION}

This study set out to identify what pre- and postoperative cephalometric characteristics might help predict an OSAS patient's response to MMA and also which outcome variables might predict a higher success rate.

Table 3. Differences between preoperative and postoperative cephalometric values and means of differences

\begin{tabular}{l|c|c|c|c|c|c}
\hline \multirow{2}{*}{ SNA } & \multicolumn{2}{|c|}{ Preoperative } & \multicolumn{2}{c|}{ Postoperative } & \multicolumn{2}{c}{ Mean of difference } \\
\cline { 2 - 7 } & Mean & SD & Mean & SD & Mean & SD \\
\hline SNB & 79.9 & 4.3 & 85.9 & 8.5 & 6 & 3.2 \\
\hline ANB & 74.3 & 4.9 & 78.5 & 5 & 4.2 & 2.2 \\
\hline PAS & 5.6 & 2.9 & 7.4 & 2.1 & 1.8 & 3.8 \\
\hline MP-H & 5 & 2.2 & 9.5 & 3.3 & 4.4 & 3.7 \\
\hline Co-A & 28.2 & 5.4 & 29.5 & 5.8 & 1.3 & 2.5 \\
\hline Co-Pog & 119 & 9.9 & 92.2 & 11.3 & 5.2 & 4.5 \\
\hline
\end{tabular}

$\mathrm{SNA}=$ angle between sella, nasion and subspinale point $\mathrm{A} ; \mathrm{SNB}=$ angle between sella, nasion and supramentale point $\mathrm{B} ; \mathrm{ANB}=$ angle between the maxilla and the mandible; PAS = the narrowest distance between the base of the tongue and the posterior pharyngeal wall; $\mathrm{MP}-\mathrm{H}=$ distance from the mandibular plane to the most anterior point of the hyoid bone); Co-A = amount of the maxillary advancement; $\mathrm{Co}-\mathrm{Pog}=$ amount of the mandibular advancement; $\mathrm{SD}=$ standard deviation. 
Table 4. Correlation between polysomnographic and cephalometric variables

\begin{tabular}{|c|c|c|c|c|}
\hline Parameter & Correlation with AHI & P-value ${ }^{a}$ & Correlation with LSAT & P-value ${ }^{a}$ \\
\hline \multicolumn{5}{|c|}{ Cephalometric variables } \\
\hline SNA & -0.62 & 0.01 & 0.18 & 0.53 \\
\hline SNB & -0.48 & 0.07 & 0.13 & 0.27 \\
\hline ANB & -0.27 & 0.33 & 0.33 & 0.22 \\
\hline PAS & -0.09 & 0.74 & 0.38 & 0.16 \\
\hline MP-H & -0.38 & 0.16 & 0.03 & 0.89 \\
\hline \multicolumn{5}{|c|}{ Maxillary and mandibular advancement } \\
\hline Co-A & -0.24 & 0.39 & -0.57 & 0.03 \\
\hline Co-B & -0.09 & 0.74 & -0.61 & 0.02 \\
\hline
\end{tabular}

aP $<0.05$ was considered statistically significant for all analyses. Wilcoxon signed rank test was used to determine the correlation between the PSG variables and the cephalometric variables for each of the outcome measures.

$\mathrm{AHI}=$ Apnea/hypopnea index; LSAT = lowest oxygen saturation; SNA = angle between sella, nasion and subspinale point $\mathrm{A} ; \mathrm{SNB}=$ angle between sella, nasion and supramentale point $\mathrm{B} ; \mathrm{ANB}=$ angle between the maxilla and the mandible; PAS = narrowest distance between the base of the tongue and the posterior pharyngeal wall; $\mathrm{MP}-\mathrm{H}=$ distance from the mandibular plane to the most anterior point of the hyoid bone; Co-A = amount of maxillary advancement; Co-Pog = amount of mandibular advancement.

As shown in the previous OSA surgical literature [13], success corresponds to an AHI of less than 20 and/or an at least $50 \%$ reduction of $\mathrm{AHI}$ from the preoperative level. On this basis, the therapy could be deemed successful in all the 15 patients undergoing MMA in our study (13 had an AHI $<20$ after surgery and the other two recorded a $50 \%$ reduction).

Comparison of the pre- and postoperative PSG results showed a clear improvement in all patients after MMA surgery. Albeit in a small sample, we therefore recorded a $100 \%$ success rate of MMA, which is similar to the findings of previous studies which reported success rates ranging from $95 \%$ to $98 \%[\underline{21}, \underline{26}]$. In accordance with the findings of a recent meta-analysis led by Holty and Guilleminaul [13], the mean overall LSAT level increased from $71 \%$ to $90 \%$. The results of the present study also showed a statistically significant increase in the SNA in all the successfully treated cases $(\mathrm{P}=0.01)$. This implies that the improvement in a patient's respiratory symptomatology is affected by the amount of SNA increase. As reported in several publications [22], bimaxillary advancement surgery has been successfully used to correct craniofacial skeletal anomalies in OSAS patients, inducing a regression of the syndrome. Nevertheless, some authors $[27,28]$ concluded that MMA can be considered a treatment option in OSAS patients without cephalometrically defined maxillomandibular deficiency; it has been shown to be a successful therapeutic option for moderate or severe OSAS patients even in absence of skeletal and $\backslash$ or occlusal anomalies. In this study, nine patients had presurgical skeletal Class II malocclusion $\left(\right.$ ANB $>4^{\circ}$ ), five patients Class I malocclusion (ANB $=2^{\circ} \pm 2^{\circ}$ ), and only one patient Class III (ANB $<0^{\circ}$ ) malocclusion. A comparable study of a population of 82
OSAS patients found that only one-third were diagnosed as skeletal Class II, $60 \%$ as Class I and $10 \%$ as Class III [29]. The surgical correction of our Class III patient resulted in less anterior movement of the mandible than is typical in MMA surgery. Although the mandibular advancement in this patient was only $3 \mathrm{~mm}$, the AHI decreased from 44 to 7 events per hour, thus confirming that MMA surgery is indicated not only in Class II, but also in Class I and in Class III malocclusion, as previously demonstrated by others [15].

Other recent studies, moreover, have pinpointed characteristics useful for identifying which patients might benefit from MMA. One of these characteristics is the presence of pharyngeal narrowing in the basal lingual area with retrognathia, especially when the length of the PAS at the level of the mandibular base is less than $11 \mathrm{~mm}[\underline{30}]$ or less than $9 \mathrm{~mm}[\underline{22}]$ and the SNB is less than $77^{\circ}$. Hochban and Brandenburg [31] suggest other traits based on cephalometric measurements, such as pharyngeal narrowing in combination with a retrognathic or dolicofacial profile. Holty and Guilleminault [13], through a systematic review and a meta-analysis including 627 OSAS adults, found that no pre- or postoperative cephalometric measurements, with the exception of a wider PAS, were predictive of successful MMA surgery. The only predictive factors noted were the degree of maxillary advancement, similar to our own findings, in association with a lower preoperative body mass index, young age and female gender. Our findings confirm that mandibular movement does not influence the response to MMA. Instead, it is the change in SNA that determines the improvement in the respiratory symptoms. In our study the mandibular plane to hyoid bone distance did not show a significant change, thus supporting the findings of Gale at al. [32]. 
The width of the PAS was measured as the narrowest distance between the base of the tongue and the posterior pharyngeal wall, which is not related to any skeletal structures [33]. This value increased from $5 \pm 2.2 \mathrm{~mm}$ to $9.5 \pm 3.3 \mathrm{~mm}$, replicating the findings of other studies [13] and thus demonstrating that the dimension of the airway increased after surgery.

\section{CONCLUSIONS}

Several published data support bimaxillary advancement as the most effective available surgical option for treating OSA patients; therefore MMA may be considered, in certain cases, the first-line approach in these subjects. The patients treated in our study, regardless of their skeletal anomalies, experienced a remarkable regression of their symptoms. Our findings suggest that the improvement in the respiratory symptoms is correlated to the increase in the SNA after surgery. This factor could help surgeons to plan surgical interventions on OSAS patients in advance, allowing them to define the amount of maxillary advancement required. Further research in a larger sample is needed to increase the predictive precision and significance of the results with a view to clinical application.

\section{AKNOWLEDGEMENT AND DISCLOSURE STATEMENTS}

The authors report no conflict of interest related to the present study. The authors would like to thank Dr Sandro Veronesi (Department of Statistics University of Insubria) for his help in processing the statistical data.

\section{REFERENCES}

1. Strollo PJ, Rogers RM. Obstructive sleep apnea. N Eng J Med. 1996 Jan11;334(2):99-104. [Medline: $\underline{8531966]}$ [doi: 10.1056/NEJM199601113340207]

2. Epstein LJ, Kristo D, Strollo PJ Jr, Friedman N, Malhotra A, Patil SP, Ramar K, Rogers R, Schwab RJ, Weaver EM, Weinstein MD. Clinical guideline for the evaluation, management and long-term care of obstructive sleep apnea in adults. J Clin Sleep Med. 2009 Jun15;5(3):263-76. [Medline: 19960649]

3. Zucconi M, Caprioglio A, Calori G, Ferrini-Strambi L, Oldani A, Castronovo C, Smirne S. Craniofacial modifications in children with habitual snoring and obstructive sleep apnoea: a case-control study. Eur Respir J. 1999 Feb;13(2):411-7. [Medline: 10065690] [doi: 10.1183/09031936.99.13241199]

4. Riley R, Guilleminault C, Herrab J, Powell N. Cephalometric airway analyses and flow-volume loops in obstructrive sleep apnea patients. Sleep. 1983;6(4):303-11. [Medline: 6665392]

5. Caprioglio A, Levrini L, Nosetti L, Berini J, Macchi A, Tagliabue A, Tettamanti L. Prevalence of malocclusion in preschool and primary school children with habitual snoring and sleep-disordered breathing. Eur J Pediatr Dent. 2011 Dec;12(4):267-71. [Medline: 22185254]

6. Tangugsorn V, Skatvedt O, Krogstad O, Lyberg T. Obstructive sleep apnoea: a cephalometric study. Part II Uvuloglossopharyngeal morphology. Eur J Orthod. 1995 Feb;17(1):57-67. [Medline: 7737346] [doi: 10.1093/ejo/17.1.57]

7. Caprioglio A, Zucconi M, Calori G, Troiani V. Habitual snoring, OSA and craniofacial modification. Orthodontic, clinical and diagnostic aspects in a case control study. Minerva Stomatol. 1999 Apr;48(4):125-37. [Medline: 10431534]

8. Battagel JM, L'Estrange PR. The cephalometric morphology of patients with obstructive sleep apnoea (OSA). Eur J Orthod. 1996 Dec;18(6):557-69. [Medline: 9009420] [doi: 10.1093/ejo/18.6.557]

9. Lye KW, Waite PD, Meara D, Wang D. Quality of life evaluation of maxillomandibular advancement surgery for treatment of obstructive sleep apnea. J Oral Maxillofac Surg. 2008 May;66(5):968-72. [Medline: 18423288] [doi: 10.1016/j.joms.2007.11.031]

10. Pirklbauer K, Russmueller G, Stiebellehner L, Nell C, Sinko K, Milesi G, Klug C. Maxillomandibular advancement for treatment of obstructive sleep apnea syndrome: a systematic review. J Oral Maxillofac Surg. 2011 Jun;69(6):165-76. [Medline: 21605790] [doi: 10.1016/ij.joms.2011.01.038]

11. Yaggi HK, Concato J, Kernan WN, Lichtman JH, Brass LM, Mohsenin V. Obstructive sleep apnea as a risk factor for stroke and death. N Engl J Med. 2005 Nov 10;353(19): 2034-41. [Medline: 16282178] [doi: 10.1056/NEJMoa043104]

12. Won CH, Li KK, Gulleminault C. Surgical treatment of obstructive sleep apnea: upper airway and maxillomandibular surgery. Proc Am Thorac Soc. 2008 Feb 15;1(2)5:193-9. [Medline: 18250212] [doi: 10.1513/pats.200708-121MG]

13. Holty J-C, Guilleminault C. Maxillomandibular advancement for treatment of obstructive sleep apnea: A systematic review and meta analysis. Sleep Med Rev. 2010 Oct;14(5):287-97. Epub 2010 Mar 2. [Medline: 20189852] [doi: 10.1016/j.smrv.2009.11.003]

14. Hoffstein V. Review of oral appliances for treatment of sleep-disordered breathing. Sleep Breath. 2007 Mar; 11(1):1-22. [Medline: 17136406] [doi: 10.1007/s11325-006-0084-8] [FREE Full Text] 
15. Ronchi P, Novelli G, Colombo L, Valsecchi S, Oldani A, Zucconi M, Paddeu A. Effectivness of maxillo-mandibular advancement in obstructive sleep apnea patients with and without skeletal anomalies. Int J Oral Maxillofac Surg. 2010 Jun;39(6):541-7. [Medline: 20434311] [doi: 10.1016/j.ijom.2010.03.006]

16. Li KK, Guilleminault C, Riley RW, Powell NB. Obstructive sleep apnea and maxillomandibular advancement: an assessment of airway changes using radiographic and nasopharyngoscopic examination. J Oral Maxillofac Surg. 2002 May;60(5):526-30. [Medline: 11988930] [doi: 10.1053/joms.2002.31849]

17. Bettega G, Pepin JL, Veale D, Deschaux C, Raphael B, Levy P. Obstructive sleep apnea syndrome. Fifty-one consecutive patients treated by maxillofacial surgery. Am J Respir Crit Care Med. 2000 Aug;162(2 pt 1): 641-9. [Medline: 10934100] [doi: 10.1164/ajrccm.162.2.9904058]

18. Meslemani D, Jones LR. Skeletal surgery in sleep apnea. Curr Opin Otolaryngol Head Neck Surg. 2011 Aug;19(4):30711. [Medline: 21659878] [doi: 10.1097/MOO.0b013e328348842e]

19. Li KK, Riley RW, Powell NB, Gervacio L, Troell RJ, Guilleminault C. Obstructive sleep apnea surgery: patient perspective and polysomnography results. Otoryngol Haad Neck Surg. 2000 Nov; 123(5):572-5. [Medline: 11077343] [doi: $10.1067 /$ mhn.2000.110107]

20. De Souza Carvalho AC, Magro Filho O, Garcia IR Jr, Araujo PM, Nogueira RL. Cephalometric and three-dimensional assessment of superior posterior airway space after maxillomandibular advancement. Int. J. Oral Maxillofac Surg. 2012 Sep;41(9):1102-11. [Medline: 22695237] [doi: 10.1016/j.ijom.2012.05.009]

21. Li KK. Maxillomandibular Advancement for obstructive sleep apnea. J Oral Maxillofac Surg. 2011 Mar;69(3):687-94. Epub 2010 Dec 24. [Medline: 21185642] [doi: 10.1016/j.joms.2010.09.014]

22. Prinsell JR. Primary and secondary telegnathic maxillomandibular advancement, with or without adjunctive procedures, for obstructive sleep apnea in adults: a literature review and treatment recommendations. J Oral Maxillofac Surg. 2012 Jul;70(7):1659-77. Epub 2011 Aug 19. [Medline: 21855196] [doi: 10.1016/j.joms.2011.03.064]

23. Prinsell JR. Maxillomandibular advancement surgery in a site-specific treatment approach for obstructive sleep apnea in 50 consecutive patients. Chest. 1999 Dec;116(6):1519-29. [Medline: 10593771] [doi: 10.1378/chest.116.6.1519]

24. Dahlberg G. Statistical methods for medical and biological students. London, United Kingdom: Allen and Unwin; 1940. p. $122-32$.

25. Houston WBJ. The analysis of errors in orthodontic measurements. Am J Orthod. 1983 May;83(5):382-90. [Medline: 6573846] [doi: 10.1016/0002-9416(83)90322-6]

26. Riley RW, Powell NB, Guilleminault C. Obstructive sleep apnea syndrome: a review of 306 consecutively treated surgical patients. Otolaryngol Head Neck Surg. 1993 Feb;108(2):117-25. [Medline: $\underline{8441535]}$

27. Li KK, Riley RW, Powell MD, Guilleminault C. Maxillomandibular advancement for persistent obstructive sleep apnea after phase I surgery in patients without maxillomandibular deficiency. Laryngoscope. 2000 Oct;110(10 pt 1):1684-8. [Medline: 11037825] [doi: 10.1097/00005537-200010000-00021]

28. Liu SR, Yi HI, Guan J, Chen B, Wu HM, Yin SK. Changes in facial appearance after maxillomandibular advancement for severe obstructive sleep apnoea hypopnea syndrome in Chinese patients: a subjective and objective evaluation. Int.J.Oral Maxillofac.Surg. 2012 Sep;41(9):1112-9. Epub 2012 Apr 13. [Medline: 22503563] [doi: 10.1016/j.ijom.2012.03.011]

29. Ingman T, Nieminen T, Hurmerinta K. Cephalometric comparison of pharyngeal changes in subjects with upper airway resistance syndrome or obstructive sleep apnoea in upright and supine positions. Eur J Orthod. 2004 Jun;26(3):321-6. [Medline: 15222718] [doi: 10.1093/ejo/26.3.321]

30. Conradt R, Hochban W, Brandenburg U, Heitmann J, Peter JH. Long-term follow-up after surgical treatment of obstructive sleep apnoea by maxillomandibular advancement. Eur Respir J. 1997 Jan;10(1):123-8. [Medline:9032503] [doi: 10.1183/09031936.97.10010123]

31. Hochban W, Brandenburg U. Morphology of the viscerocranium in obstructive sleep apnoea syndrome - cephalometric evaluation of 400 patients. J Oral Maxillofac Surg. 1994 Aug;22(4):205-13. [Medline: 7962567]

32. Gale A, Kilpelainen PV, Laine Alava MT. Hyoid bone position after surgical mandibular advancement. Eur J Orthod. 2001 Dec;23(6):695-701. [Medline: 11890065 ] [doi: $10.1093 /$ ejo/23.6.695]

33. Solow B, Skov S, Ovesen J, Norup PW, Wildschiødtz G. Airway dimensions and head posture in obstructive sleep apnea. Eur J Orthod. 1996. Dec;18(6):571-9. [Medline: 9009421]

\section{To cite this article:}

Ronchi P, Cinquini V, Ambrosoli A, Caprioglio A. Maxillomandibular Advancement in Obstructive Sleep Apnea Syndrome Patients: a Restrospective Study on the Sagittal Cephalometric Variables .

J Oral Maxillofac Res 2013;4(2):e5

URL: http://www.ejomr.org/JOMR/archives/2013/2/e5/v4n2e5ht.pdf

doi: $\underline{10.5037 / j o m r .2013 .4205}$ 
Copyright (C) Ronchi P, Cinquini V, Ambrosoli A, Caprioglio A. Accepted for publication in the JOURNAL OF ORAL \& MAXILLOFACIAL RESEARCH (http://www.ejomr.org), 29 June 2013.

This is an open-access article, first published in the JOURNAL OF ORAL \& MAXILLOFACIAL RESEARCH, distributed under the terms of the Creative Commons Attribution-Noncommercial-No Derivative Works 3.0 Unported License, which permits unrestricted non-commercial use, distribution, and reproduction in any medium, provided the original work and is properly cited. The copyright, license information and link to the original publication on (http://www.ejomr.org) must be included. 